\title{
Tissue trauma and inflammatory response following laparoscopic versus abdominal hysterectomy: a prospective randomized clinical trial
}

\author{
Ahmed M. Abbas, Khaled H. Swidan, Ahmed M. Ali, Mohamed S. Sweed*
}

Department of Obstetrics and Gynecology, Faculty of Medicine, Ain Shams University, Cairo, Egypt

Received: 01 September 2020

Accepted: 16 September 2020

\section{*Correspondence:}

Dr. Mohamed S. Sweed,

E-mail: drmsweed@med.asu.edu.eg

Copyright: (C) the author(s), publisher and licensee Medip Academy. This is an open-access article distributed under the terms of the Creative Commons Attribution Non-Commercial License, which permits unrestricted non-commercial use, distribution, and reproduction in any medium, provided the original work is properly cited.

\begin{abstract}
Background: Laparoscopic surgery is associated with more favorable clinical outcome than conventional open surgery. This might be related to the magnitude of tissue trauma and tissue stress response. This study compares the intensity of tissue injury by assessing plasma C-reactive protein (CRP), lactic dehydrogenase (LDH), and cancer antigen 125 (CA 125 ) in patients undergoing laparoscopic hysterectomy compared to abdominal hysterectomy.

Methods: This study was conducted at Ain Shams University Maternity Hospital from May 2018 to February 2020.74 women candidate for hysterectomy were recruited and randomized into two groups: group A included 37 cases who underwent abdominal hysterectomy, and group B included 37 cases that underwent laparoscopic hysterectomy.

Results: CRP, LDH and CA125 significantly increased post-operatively in both groups. Postoperative mean serum CRP, LDH and CA125 were significantly higher in the laparotomy group $(10.84 \pm 2.47,262.21 \pm 76.77$, and $13.41 \pm 2.6$ respectively) compared to laparoscopy group $(7.92 \pm 2.25,148.53 \pm 43.56,11.79 \pm 2.77$ respectively) $(\mathrm{p}<0.05)$.

Conclusions: Surgery is a significant cause of tissue injury that can be assessed by specific markers. We suggest that laparoscopic surgery causes less tissue damage as assessed by lower postoperative CRP and LDH values, which might account for the earlier recovery and reduced hospital stay in laparoscopic surgery.
\end{abstract}

Keywords: Abdominal hysterectomy, Cancer antigen 125, C-reactive protein, Lactic dehydrogenase, Laparoscopic hysterectomy, Surgical stress

\section{INTRODUCTION}

Surgical trauma and particularly the surgical trauma associated with major operations, elicits characteristic profound physiologic changes that involve the metabolic, inflammatory, and immune reactions that lead to widespread changes in the functioning of body organs. This overall effect is commonly referred to as the stress response to surgery. ${ }^{1}$

The magnitude of the stress response is roughly proportional to the severity of surgery and this has an influence on the postoperative complications and the patients' convalescence and morbidity, therefore, many investigators have attempted to find ways to evaluate the stress response to surgery. ${ }^{2}$
Hysterectomy is the most common major gynecologic operation performed worldwide, with two main approaches for benign uterine diseases: abdominal hysterectomy and laparoscopic hysterectomy. ${ }^{3}$ Since first documented in 1989, laparoscopic hysterectomy has gradually become a popular alternative to the abdominal procedure. ${ }^{4}$ Laparoscopic hysterectomies has been established as a safe and reliable procedure in routine clinical practice. ${ }^{5}$

Laparoscopic approach is either used to facilitate the ease of vaginal delivery of the uterus as in laparoscopy assisted vaginal hysterectomy (LAVH), or all the steps of hysterectomy are done laparoscopically as in total laparoscopic hysterectomy (TLH). Although it may take more operative time, it is associated with less 
intraoperative blood loss, reduced hospital stay, and earlier return to normal activities as compared to abdominal hysterectomy. ${ }^{6}$ The technique of hysterectomy can be selected on the basis of indication of surgery, experience of the surgeon, and patient preference.

Surgical trauma stimulates a tissue response, the intensity of which is proportional to the extent of trauma. When trauma causes cell damage and necrosis, intracellular contents tend to leak out into the extracellular space, which thereafter move into the plasma either directly or via lymphatics. ${ }^{7}$ The degree of surgical trauma can be assessed by measuring plasma levels of specific proteins and enzymes associated with tissue damage, such as creatine phosphokinase (CPK), C-reactive protein (CRP), lactic dehydrogenase (LDH), cancer antigen 125 (CA 125), tumor necrosis factor- $\alpha$ (TNF- $\alpha$ ), and interleukin 6 (IL-6). ${ }^{8}$ Compared with laparotomy, laparoscopic surgery is assumed to be associated with less surgical trauma, due to the smaller abdominal incision and less tissue manipulation. ${ }^{9}$ This study was conducted to compare the intensity of tissue injury by assessing the plasma levels of CRP, LDH, and CA 125 in patients undergoing laparoscopic hysterectomy, compared with those undergoing abdominal hysterectomy.

\section{METHODS}

This prospective randomized clinical trial was conducted at Ain Shams University Maternity Hospital, Cairo, Egypt from May 2018 to February 2020. Women candidate for hysterectomy for benign gynecological disease were assessed for eligibility. Women with uterine size $>14$ weeks, uterine descent or considered suitable for vaginal hysterectomy, body mass index $(\mathrm{BMI})>35 \mathrm{~kg} / \mathrm{m}^{2}$, cardiac or chest conditions prohibiting the laparoscopic procedure, and medical conditions associated with tissue breakdown e.g. inherited hemolytic disorders, bleeding disorders were excluded from the study. Informed written consent was obtained from all women before participating in the study. The study was approved by Ain Shams University, Faculty of Medicine, Research Ethics Committee (FMASU M D 244/2018).

Sample size was calculated using PASS $®$ version 15.0, setting the power $(\beta)$ at 0.02 and significance level $(\alpha)$ at 0.05 . Data from previous study indicated that mean postoperative concentrations of CRP following laparoscopy and laparotomy were $7.0 \pm 3.5 \mathrm{mg} / \mathrm{dl}$ and $10.6 \pm 4.3 \mathrm{mg} / \mathrm{dl}$ respectively. ${ }^{10} \mathrm{~A}$ minimal sample size of 68 women was calculated, and assuming a drop-out rate of $10 \%$, a minimum drop-out inflated enrollment sample size of approximately 74 women was calculated.

After enrollment, women were randomized equally to either laparoscopic or abdominal hysterectomy using computer-generated list with block randomization ratio 1:1. All patients were assessed for inclusion and exclusion criteria. Operative interventions were performed under general anesthesia by surgeons experienced in both laparoscopic and abdominal surgery. Women received preoperative prophylactic intravenous antibiotic, cefotaxime hydrochloride $2 \mathrm{gm}$ (Cefotax ${ }^{\circledR}$, EIPICO, Egypt), 30 minutes before the start of surgery, and the bladder was drained with a Foley catheter. In the abdominal surgery, a pfannenstiel abdominal incision was performed, bilateral cutting and ligation of round and infundibulo-pelvic ligaments, dissection of uterovesical peritoneum, bilateral cutting and ligation of uterine arteries and cardinal-uterosacral ligaments was done followed by closure of the vaginal cuff and closure of anterior abdominal wall in layers.

Laparoscopy was performed in lithotomy position, using one 10 -mm umbilical port, one 5-mm supra-pubic midline port, and two 5-mm ports in right and left lower quadrants. Mangeshikar uterine manipulator was used for uterine manipulation. After performing a thorough pelvic examination, round ligaments and broad ligaments were electro-dissected by a tripolar forceps (Ligasure®) in 25 cases while a bipolar forceps and scissors were used in the remaining 9 cases. Uterovesical peritoneum was dissected using sharp or blunt dissection when appropriate. After visualizing the course of the ureter, an opening was made in the posterior leaflet of the broad ligament and extended down to the uterosacral ligaments. Subsequently infundibulopelvic or utero-ovarian ligaments were electrodissected. Uterine vessels and cardinal-uterosacral ligaments were electro cauterized and cut. The uterus was delivered vaginally and vagina was closed by running sutures. Intraoperative blood loss, operation time, hospital stay, operative complications, and post-operative Hemoglobin were recorded. Intraoperative blood loss was estimated by measuring the aspirated blood in the laparoscopy group, which was calculated by subtracting the volume of the irrigation fluid used from the total aspirated volume. In the laparotomy group, blood loss was measured as the sum of aspirated volume and difference in weighed surgical swabs in grams (wet post-operative swabs - clean preoperative swabs).

Blood samples for assay of markers of tissue injury including CRP, LDH, and CA 125 were taken the day of surgery at 8:00 a.m. and on post-operative days 1 and 2 . CA 125 was measured using appropriate radioimmunoassay kits (Roche Elecsys ${ }^{\circledR}$ automated electrochemiluminescence immunoassay and analyzed by COBAS auto analyzer), $\mathrm{LDH}$, was measured by quantitative determination in human serum on Beckman Coulter AU analyzers. Plasma CRP concentration was determined using Beckman Coulter AU analyzers for quantitative determination of CRP in human serum.

Data were analyzed using Statistical Package for the Social Sciences (SPSS) version 24.0 (Inc., Chicago, IL, USA). Continuous numerical variables were presented as mean \pm standard deviation (SD) and inter-group differences were compared using the unpaired t test. Categorical variables were presented as number and percentage. Nominal data were compared using the Pearson chi- 
squared test or Fisher's exact test. Ordinal data were compared using the chi-squared test for trend. $\mathrm{P}$ values $<0.05$ are considered statistically significant.

\section{RESULTS}

There was no difference in demographic characteristics, preoperative hemoglobin or previous pelvic surgeries between the groups (Table 1). Six patients were excluded from the analysis; three patients in the laparoscopy group, one because of conversion to laparotomy due to extensive adhesions, another for a ureteric injury that was managed conservatively and the last was discharged before completing the analysis. Also, three patients in the laparotomy group were excluded owing to bladder injury in two cases and post-operative discharge on demand before analysis in another case (Figure 1). Mean intraoperative blood loss was $295.88 \pm 55.15 \mathrm{ml}$ and $354.12 \pm 35.41 \mathrm{ml}(\mathrm{p}<0.0001$, CI $95 \%$; 35.799 to 80.681$)$ and mean operation time was $119.71 \pm 9.85$ minutes and $83.82 \pm 11.95$ minutes ( $\mathrm{p}<0.0001$, CI 95\%; -41.193 to 30.587 ) in the laparoscopy and laparotomy groups, respectively. Duration of hospital stay was significantly shorter in the laparoscopy group compared with the laparotomy group $2.18 \pm 0.38$ days and $3.82 \pm 0.66$ days $(\mathrm{p}<0.0001$, CI 95\%; 1.3792 to 1.9008$)$. Also mean postoperative hemoglobin drop was significantly less in laparoscopy group compared to laparotomy $0.98 \pm 0.42$ gm\% and was $1.67 \pm 0.29 \mathrm{gm} \%(\mathrm{p}<0.0001$, CI $95 \%$; 0.515 to 0.865$)$. However, there was necessity of blood transfusion for 2 patients who had total laparoscopic hysterectomy (TLH) and for 4 patients who had total abdominal hysterectomy (TAH), this was not statistically significant. Two patients who had TLH and 5 patients who had TAH had transient post-operative fever with no statistical significance as well.

With regard to the parameters of tissue injury, compared with baseline values, in both groups there were significant increases in the first and second postoperative days in the levels of CRP (Table 2). LDH significantly increased in the first day postoperative in both groups, but rapidly declined to show insignificant difference between preoperative measures in the TLH group (Table 2). Both groups showed a significant increase in CA 125 in the first and second post-operative days (Table 3). When we compared the groups, mean plasma levels of CRP, LDH and CA 125 were found to be significantly higher in the laparotomy group both on post-operative days 1 and 2 , compared with the laparoscopy group (Table 2 and 3 ).

Table 1: Pre-operative characteristics of both groups.

\begin{tabular}{|c|c|c|c|c|}
\hline Pre-operative characteristics & TAH $(\mathbf{N}=\mathbf{3 4})$ & TLH $(\mathbf{N}=34)$ & p value & CI $95 \%$ \\
\hline Age (years), mean \pm SD & $45.68 \pm 2.66$ & $45.38 \pm 2.54$ & 0.64 & -1.559 to 0.959 \\
\hline Rarity (IQ), median & $3(1)$ & $3(1.25)$ & 0.73 & 0.801 to 0.816 \\
\hline BMI $\left(\mathrm{kg} / \mathrm{m}^{2}\right)$, mean \pm SD & $29.15 \pm 1.44$ & $29.14 \pm 1.89$ & 0.98 & -0.824 to 0.804 \\
\hline Previous pelvic surgery number (\%) & $6 / 34(18)$ & $8 / 34(24)$ & 0.55 & \\
\hline Preoperative haemoglobin $(\mathrm{gm} \%)$, mean \pm SD & $10.71 \pm 0.67$ & $10.79 \pm 0.76$ & 0.65 & -0.267 to 0.427 \\
\hline
\end{tabular}

Table 2: Pre-operative and post-operative changes in the markers of tissue injury (CRP and LDH).

\begin{tabular}{|c|c|c|c|c|}
\hline & TAH $(\mathbf{N}=34)$ & TLH $(\mathbf{N}=34)$ & p value & CI $95 \%$ \\
\hline \multicolumn{5}{|l|}{ CRP, mean \pm SD $($ gm/dl) } \\
\hline Preoperative (a) & $0.82 \pm 0.29$ & $0.62 \pm 0.27$ & 0.0045 & -0.336 to -0.0643 \\
\hline 1 day postoperative (b) & $10.84 \pm 2.47$ & $7.92 \pm 2.25$ & $<0.0001$ & -4.064 to -1.776 \\
\hline 2 days postoperative (c) & $13.97 \pm 3.12$ & $9.8 \pm 2.43$ & $<0.0001$ & -5.524 to -2.816 \\
\hline P value; CI $95 \%$ (a versus b) & $\begin{array}{l}<0.0001 \\
9.168 \text { to } 10.872\end{array}$ & $\begin{array}{l}<0.0001 \\
6.524 \text { to } 8.076\end{array}$ & & \\
\hline P value; CI 95\% (a versus c) & $\begin{array}{l}<0.0001 \\
12.077 \text { to } 14.223\end{array}$ & $\begin{array}{l}<0.0001 \\
8.343 \text { to } 10.017\end{array}$ & & \\
\hline P value; CI $95 \%$ (b versus c) & $\begin{array}{l}<0.0001 \\
1.767 \text { to } 4.493\end{array}$ & $\begin{array}{l}0.0015 \\
0.746 \text { to } 3.014\end{array}$ & & \\
\hline \multicolumn{5}{|l|}{ LDH, mean+SD (gm/dl) } \\
\hline Preoperative (a) & $84.79 \pm 16.1$ & $77.88 \pm 15.09$ & 0.0724 & -14.466 to 0.646 \\
\hline 1 day postoperative (b) & $262.21 \pm 76.77$ & $148.53 \pm 43.56$ & $<0.0001$ & -143.903 to -83.457 \\
\hline 2 days postoperative (c) & $196.32 \pm 69.18$ & $83.94 \pm 17.99$ & $<0.0001$ & -136.856 to -87.904 \\
\hline P value; CI $95 \%$ (a versus b) & $\begin{array}{l}<0.0001 \\
150.561 \text { to } 204.279\end{array}$ & $\begin{array}{l}<0.0001 \\
54.865 \text { to } 86.435\end{array}$ & & \\
\hline P value; CI 95\% (a versus c) & $\begin{array}{l}<0.0001 \\
87.209 \text { to } 135.851\end{array}$ & $\begin{array}{l}0.1371 \\
-1.98 \text { to } 14.1 \\
\end{array}$ & & \\
\hline P value; CI 95\% (b versus c) & $\begin{array}{l}0.0004 \\
-101.275 \text { to }-30.505\end{array}$ & $\begin{array}{l}0.0015 \\
-80.727 \text { to }-48.453 \\
\end{array}$ & & \\
\hline
\end{tabular}


Table 3: Preoperative and postoperative changes in CA 125.

\begin{tabular}{|c|c|c|c|c|}
\hline & TAH $(n=34)$ & TLH $(n=34)$ & P value & CI 95\% \\
\hline \multicolumn{5}{|l|}{ CA 125, mean \pm SD $(\mathrm{gm} / \mathrm{dl})$} \\
\hline Preoperative (a) & $9.18 \pm 1.69$ & $8.26 \pm 1.69$ & 0.0282 & -1.738 to -0.102 \\
\hline 1 day postoperative (b) & $13.41 \pm 2.6$ & $11.79 \pm 2.77$ & 0.0154 & -2.921 to -0.319 \\
\hline 2 days postoperative (c) & $11.38 \pm 1.66$ & $10.29 \pm 2.11$ & 0.0209 & -2.009 to -0.171 \\
\hline P value; CI 95\% (a versus b) & $\begin{array}{l}<0.0001 \\
3.168 \text { to } 5.292\end{array}$ & $\begin{array}{l}<0.0001 \\
2.419 \text { to } 4.641\end{array}$ & & \\
\hline P value; CI 95\% (a versus c) & $\begin{array}{l}<0.0001 \\
1.389 \text { to } 3.011\end{array}$ & $\begin{array}{l}<0.0001 \\
1.104 \text { to } 2.956\end{array}$ & & \\
\hline P value; CI $95 \%$ (b versus c) & $\begin{array}{l}0.0003 \\
-3.086 \text { to }-0.974\end{array}$ & $\begin{array}{l}0.0145 \\
-2.692 \text { to }-0.308\end{array}$ & & \\
\hline
\end{tabular}

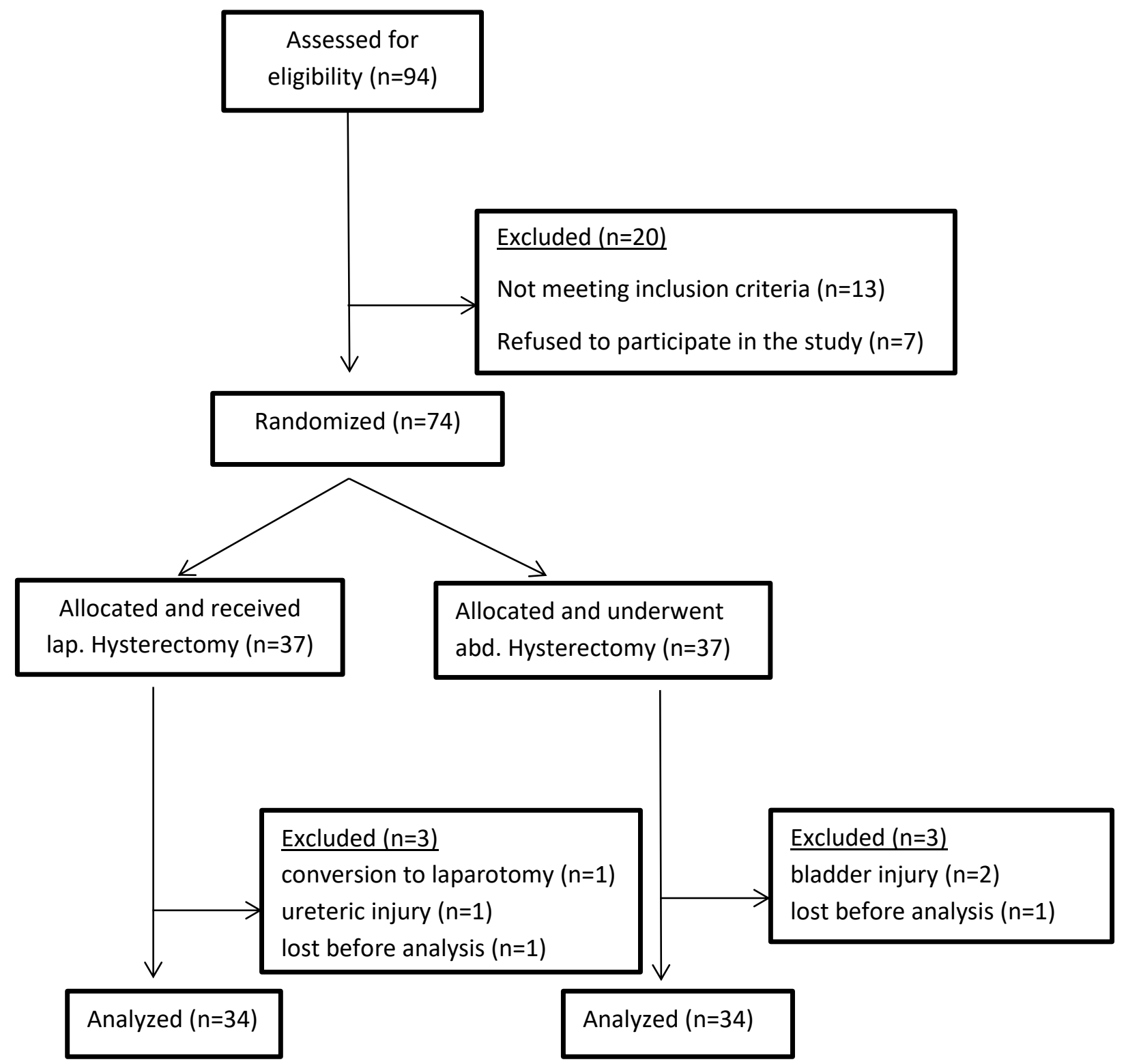

Figure 1: Flow chart of the study. 


\section{DISCUSSION}

Laparoscopic hysterectomy has largely replaced the abdominal route with vaginal removal of the specimen. The laparoscopic procedure avoids the large abdominal incision, provides shorter hospital stay, faster recovery and low rate of cuff or wound infection. ${ }^{6}$ Increasing interest in laparoscopic hysterectomy has occurred since it was first reported in $1989 .{ }^{1}$ Several studies comparing abdominal and laparoscopic hysterectomy, found the later to more beneficial in terms of lower complication rate, less postoperative pain, less blood loss, shorter hospital stay, shorter healing time and earlier return to daily activities. ${ }^{2,6}$ Still, studies report that laparoscopic hysterectomy takes longer operative time than abdominal hysterectomy. ${ }^{11,12}$ The results of the current study is in consensus of these studies.

In consensus with this study, several studies reported less intraoperative and perioperative blood loss in laparoscopic hysterectomy compared to abdominal hysterectomy. ${ }^{2,11,13}$ However, one study reported no significant difference in blood loss between TLH and TAH. ${ }^{12}$ The current study found shorter hospital stay in TLH which was similar to what was reported by other studies reporting shorter postoperative hospitalization time in laparoscopy group. $6,10,13$

This study demonstrated that TLH is associated with less tissue trauma compared with open surgery. There are some proteins and specific enzymes that may be used to predict the degree of tissue trauma, such as CRP, LDH, interleukin-6, TNF- $\alpha$, and CA125. ${ }^{12,14-15}$ Acute trauma stimulates a series of hormonal, metabolic and inflammatory changes That together constitute the stress response, and the magnitude of this response reflects the severity of tissue trauma. ${ }^{16}$

CRP is a highly conserved molecule and a member of the pentraxin family of proteins, which is secreted from the liver in response to a variety of inflammatory cytokines, mainly IL-6. ${ }^{17} \mathrm{CRP}$ increases very rapidly in response to trauma, inflammation, and infection, and returns to normal values quickly with the resolution of the condition. ${ }^{13,17}$ Thus, the measurement of CRP may be used to monitor the degree of trauma induced by surgery.

In patients undergoing hysterectomy, CRP levels were lower after laparoscopic hysterectomy than abdominal surgery. ${ }^{1,6,11,18}$ To the contrary, other researchers found no post-operative difference in CRP between abdominal and laparoscopic hysterectomy, and the authors asserted that this was related to the longer operation time or extensive electrocoagulation in the laparoscopy group. ${ }^{11}$ In agreement with previous studies, the post-operative increase in levels of CRP was significantly higher in the laparotomy group than in the laparoscopy group.

Lactic dehydrogenase is an intracellular enzyme that is found in many tissues and organs. When disease or injury affects tissues containing $\mathrm{LDH}$, the cells release this enzyme into the bloodstream. Measuring total LDH plasma levels may help determine the presence of tissue damage induced by surgical trauma. ${ }^{17}$ There is a very limited number of studies comparing the changes in serum LDH levels between laparoscopic and open surgery. One study compared serum LDH levels between laparoscopic and abdominal cholecystectomy and observed significant increase in the open surgery group compared with the laparoscopy group. ${ }^{19}$ Another, found postoperative LDH rise is more in the TAH group yet this rise is not statistically significant between both groups. ${ }^{10}$ In our study, LDH increased significantly on postoperative day 1. However, there was a statistically significant difference between the groups, being higher in laparotomy group. Increased plasma LDH after laparoscopic cholecystectomies might be attributed to high intraabdominal pressure affecting mesenteric blood flow. ${ }^{18}$ Mesenteric blood flow can also be affected in gynecological laparoscopic interventions performed in the Trendelenburg position, this might explain the postoperative rise of serum LDH.

CA 125 is a glycoprotein that was initially reported to be a marker of ovarian cancer, but later was found elevated in a number of physiologic and pathologic conditions. The postoperative rise in serum CA 125 concentration is due to a common reaction following abdominal surgery for benign reasons. Peritoneum and omentum are suggested to be sources of CA $125 .{ }^{20}$ Studies investigating postoperative changes in plasma levels of CA 125 commonly indicate that the increase is prominent after post-operative day 7, with no difference between laparoscopy and open surgery groups. ${ }^{10,14}$ In contrast, this study observed a significant postoperative rise in plasma levels of CA 125 in both groups starting from the first postoperative day and more prevalent in the laparotomy group.

\section{CONCLUSION}

In conclusion, laparoscopic hysterectomy is a safe and suitable procedure for selected women. It gives women many advantages such as: less peri-operative morbidity, shorter hospitalization time, and faster return to activity. Although the mean operation time was longer in the laparoscopy group, we found more significant increase in CRP, LDH and CA 125 levels in the laparotomy group. This implies that laparoscopic surgery results in less tissue trauma and more rapid postoperative recovery, despite a longer operating time.

\section{ACKNOWLEDGMENTS}

Authors would like to acknowledge Ain Shams University.

Funding: No funding sources

Conflict of interest: None declared

Ethical approval: The study was approved by the Institutional Ethics Committee 


\section{REFERENCES}

1. Lundin ES, Wodlin NB, Nilsson L, Theodorsson E, Ernerudh J, Kjølhede P. Markers of tissue damage and inflammation after robotic and abdominal hysterectomy in early endometrial cancer: a randomised controlled trial. Sci Rep. 2020;10(1):7226.

2. Oksuzoglu A, Seckin B, Turkcapar AF, Ozcan S, Gungor T. Comparison of tissue trauma after abdominal, vaginal and total laparoscopic hysterectomy. Ginekol Pol. 2015;86(4):268-73.

3. Wu JM, Wechter ME, Geller EJ, Nguyen TV, Visco AG. Hysterectomy rates in the United States, 2003. Obstet Gynecol. 2007;110(5):1091-5.

4. Nieboer TE, Johnson N, Lethaby A, Tavender E, Curr E, Garry R, et al. Surgical approach to hysterectomy for benign gynaecological disease. Cochrane Database Syst Rev. 2009;3:003677.

5. Schindlbeck C, Klauser K, Dian D, Janni W, Friese K. Comparison of total laparoscopic, vaginal and abdominal hysterectomy. Arch Gynecol Obstet. 2008;277(4):331-7.

6. Kim T, Lee Y, Cha HH, Kim C, Choi CH, Lee J, et al. Single-port-access laparoscopic-assisted vaginal hysterectomy versus conventional laparoscopicassisted vaginal hysterectomy: a comparison of perioperative outcomes. Surg Endosc. 2010;24(9):2248-52.

7. Watt DG, McSorley ST, Horgan PG, McMillan DC. Enhanced Recovery After Surgery: Which Components, If Any, Impact on The Systemic Inflammatory Response Following Colorectal Surgery? A Systematic Review. Medicine (Baltimore). 2015;94(36):1286.

8. Demir A, Bige O, Saatli B, Solak A, Saygili U, Onvural A. Prospective comparison of tissue trauma after laparoscopic hysterectomy types with retroperitoneal lateral transsection of uterine vessels using ligasure and abdominal hysterectomy. Arch Gynecol Obstet. 2008;277(4):325-30.

9. Drahonovsky J, Haakova L, Otcenasek M, Krofta L, Kucera E, Feyereisl J. A prospective randomized comparison of vaginal hysterectomy, laparoscopically assisted vaginal hysterectomy, and total laparoscopic hysterectomy in women with benign uterine disease. Eur J Obstet Gynecol Reprod Biol. 2010;148(2):1726.

10. Atabekoglu C, Sönmezer M, Güngör M, Aytaç R, Ortaç F, Unlü C. Tissue trauma in abdominal and laparoscopic-assisted vaginal hysterectomy. J Am Assoc Gynecol Laparosc. 2004;11(4):467-72.

11. Ellström M, Bengtsson A, Tylman M, Haeger M, Olsson JH, Hahlin M. Evaluation of tissue trauma after laparoscopic and abdominal hysterectomy: measurements of neutrophil activation and release of interleukin-6, cortisol, and C-reactive protein. J Am Coll Surg. 1996;182(5):423-30.

12. Inal ZO, Inal HA. Comparison of abdominal, vaginal, and laparoscopic hysterectomies in a tertiary care hospital in Turkey. Ir J Med Sci. 2018;187(2):485-91.

13. Giannoudis PV. Current concepts of the inflammatory response after major trauma: an update. Injury. 2003;34(6):397-404.

14. Härkki-Sirén P, Sjöberg J, Toivonen J, Tiitinen A. Clinical outcome and tissue trauma after laparoscopic and abdominal hysterectomy: a randomized controlled study. Acta Obstet Gynecol Scand. 2000;79(10):866-71.

15. Labib M, Palfrey S, Paniagua E, Callender R. The postoperative inflammatory response to injury following laparoscopic assisted vaginal hysterectomy versus abdominal hysterectomy. Ann Clin Biochem. 1997; 34(5):543-5.

16. Uccella S, Cromi A, Serati M, Casarin J, Sturla D, Ghezzi F. Laparoscopic hysterectomy in case of uteri weighing $\geq 1$ kilogram: a series of 71 cases and review of the literature. J Minim Invasive Gynecol. 2014;21(3):460-5.

17. Brøchner AC, Toft P. Pathophysiology of the systemic inflammatory response after major accidental trauma. Scand J Trauma Resusc Emerg Med. 2009; 17:43.

18. Guven HE, Oral S. Liver enzyme alterations after laparoscopic cholecystectomy. J Gastrointestin Liver Dis. 2007;16(4):391-4.

19. Mrksić M, Cabafi Z, Feher I, Mirković M. Surgical trauma in laparoscopic and classical cholecystectomy. Med Pregl. 2001;54(7-8):327-31.

20. Van der Zee AG, Duk JM, Aalders JG, Boontje AH, ten Hoor KA, de Bruijn HW. The effect of abdominal surgery on the serum concentration of the tumourassociated antigen CA 125 . Br J Obstet Gynaecol. 1990;97(10):934-8.

Cite this article as: Abbas AM, Swidan KH, Ali AM, Sweed MS. Tissue trauma and inflammatory response following laparoscopic versus abdominal hysterectomy: a prospective randomized clinical trial. Int J Reprod Contracept Obstet Gynecol 2020;9:4262-7. 